\section{O critério utilitarista será adequado para situação de risco?}

\section{Is the utilitarian criterion appropriate for situations of risk?}

Dalva Alves das Neves 1

1 Programa de Doutoramento em Bioética. Faculdade de Medicina. Universidade do Porto. Alameda Prof. Hernâni Monteiro, 4200-

319. Porto, Portugal. E-mail: dalvaaneves@hotmail.com

\begin{abstract}
Utilitarianism differs from ethical theories in which good or evil depend on the agent, since, according to utilitarian thinkers, a good action may result from bad intentions. Before Jeremy Bentham, the founder of the theory, and John Stuart Mill, its strongest advocate, gave utilitarianism its modern form, such kinds of thinking based on the principle of utility had already existed in the philosophy of the ancients. They shared the idea of building up a positive science of social facts, devoid of any quest for first principles or absolute truths.
\end{abstract}

Key words Ethics, Ethics, medical, Population at risk, Risk groups

\section{Resumo}

O utilitarismo difere das teorias éticas que fazem o caráter de bom ou mau de uma ação depender do agente, pois, de acordo com o utilitarismo, é possivel que uma ação boa venha resultar de uma motivação ruim no indivíduo. Antes de Jeremy Benthan, fundador do utilitarismo, e Stuart Mill, um dos maiores defensores desta teoria, darem forma ao utilitarismo, o pensamento utilitarista já existia na filosofia antiga inspirado na formulação do princípio da utilidade. Partilhavam a ideia de construir uma ciência positiva dos fatos sociais, afastando-se de qualquer pretensão de encontrar principios ou verdades absolutas.

Palavras-chave Ética, Ética médica, População em risco, Grupos de risco 


\section{Introdução}

O utilitarismo é um tipo de ética normativa, segundo o qual uma ação é moralmente correta se tende a promover a felicidade e condenável se tende a produzir a infelicidade, considerando não apenas a felicidade do agente da ação, mas também a de todos afetados por ela. Rejeita o egoísmo, opondo-se a que o indivíduo deva perseguir seus próprios interesses, à custa ou não dos outros, e se opõe também a qualquer teoria ética que considere ações ou tipos de atos como certos ou errados independentes das consequências que possam ter. ${ }^{1}$

O utilitarismo observa o mundo como um meio de atingir alguma finalidade deixando de lado qualquer outro valor subjetivo. É uma doutrina ética que prescreve a ação ou inação de forma a otimizar o bem-estar do conjunto dos seus indivíduos. Filosoficamente, pode-se resumir a "agir sempre de forma a produzir a maior quantidade de bem-estar" (princípio do bem-estar máximo). Trata-se de uma concepção que avalia o caráter ético de uma atividade a partir do ponto de vista de suas consequências ou resultados. Este princípio inspirou inclusive a Revolução Francesa (1789), e foi criticado por pensadores racionalistas, por exemplo, Kant, adversário da ética das consequências (princípio utilitarista). ${ }^{2}$

O utilitarismo busca a solução para conflitos éticos num caminho intermediário, preconizando a harmonização entre pontos de vistas opostos e excessivamente generalistas do mundo e procura evitar preconceitos que normalmente sustenta esses preceitos. A base deste princípio se insere nas ações de prazer e dor (na quantidade de prazer ou dor provocado por uma ação).

Numa perspectiva kantiana a regra é central (falar a verdade independente da situação, mesmo que isso seja prejudicial, por exemplo, em uma situação em que você tiver que mentir à polícia , o princípio Kantiano impede que isto possa ser feito, mesmo você sabendo que isto salvará sua vida: um judeu que na época da segunda guerra mundial tivesse de passar numa barreira alemã teria que dizer que era um judeu) já o princípio utilitarista você poderia mentir em condições especiais. Mesmo quando, no caso particular, o dizer a verdade possa ter consequências piores, do ponto de vista do utilitarismo do ato, (dizer a verdade é necessário). Existe uma ética deontológica para a qual se uniformizará a regra como um bem, independentemente da avaliação das consequências, sendo esta, uma característica típica do utilitarismo, colocando-o em contraste com todas as doutrinas que pensam que o juízo sobre o bem e o mal depende exclusivamente da existência de regras. Em uma ética consequencial, a concepção utilitarista da moralidade faz depender a moralidade das ações das suas conseqüências : se o resultado de uma ação for favorável ao maior número, então a ação será moralmente correta e moralmente incorreta se os resultados não forem positivos para maioria. Independentemente do que se tenha praticado, o valor da ação estará sempre nas vantagens que foi capaz de trazer ou nas conseqüências de sua concretização.

Um bom exemplo utilitarista pode ler-se a partir da ação terrorista de 11 de setembro de 2001, quando foram destruídas as torres gêmeas de Nova York. Nessa altura houve um quarto avião que provavelmente foi derrubado ou por uma ação do governo dos Estados Unidos ou pelas pessoas que estavam neste avião. Tanto em uma situação como em outra, foi utilizado o princípio do utilitarismo onde as vidas das pessoas que estavam no vôo, foram sacrificadas em favor de minimizar a dor de milhares de pessoas que poderiam ser mortas se o avião persistisse em sua rota.

\section{Ética da virtude: a ética da disposição de caráter do agente}

A ética da virtude originou-se na Grécia, principalmente com Aristóteles, e tem sido redescoberta por filósofos contemporâneos como Ascombe e Alasdair McIntyre. Esta teoria resume-se na frase " $O$ que vale é a intenção", e não o que o agente faz, mas as determinações de caráter que motivaram estas intenções, que vão possibilitar as pessoas viver bem em uma sociedade. 2 Essas determinações chamam-se virtudes. As virtudes podem ser morais como a bondade, o senso de justiça, a sinceridade, a honestidade, a lealdade, e não morais como a coragem, e a força de vontade. Bondade e senso de justiça são considerados, como as virtudes principais, parecendo ser essas virtudes interdependentes. As virtudes morais podem depender das não morais. Uma pessoa pode se sentir indignada com uma injustiça, porém precisará de coragem para lutar contra ela. Aristóteles entendia virtude como um justo meio entre um extremo de excesso e outro de falta em relação a cada situação, assim, ser corajoso é bom porque é um meio termo entre a covardia e a temeridade. ${ }^{2}$

Apesar da importância da virtude, é difícil admitir a tese de que as qualidades de caráter têm prioridade sobre o agir. Normalmente o valor da ação concorda com a intenção: a uma boa intenção costuma seguir-se uma boa ação e vice-versa, porém 
pode haver exceção. Defensores da ética da virtude priorizam o valor moral da intenção, contudo há casos em que o valor da intenção diverge do valor da ação e o seu efeito. O valor moral dos traços do caráter das pessoas acaba por ser definido com base no valor moral do conjunto das ações deles resultantes, e não ao contrário. O conjunto de ações não pode ser medido pela presença da virtude no agente, mais sim pelas qualidades de caráter que se definem como disposições virtuosas. É o sucesso das ações de quem possua uma certa disposição de caráter que a leva a identificar estas como virtude. O princípio formal da justiça de Aristóteles define que, iguais devem ser tratados de formas iguais e desiguais de forma desiguais. 3

\section{Ética deontológica: tipo de ação}

$\mathrm{Na}$ ética deontológica o valor moral está nas regras morais. As éticas deontológicas se tornaram predominantes durante a idade média, assim como na atualidade, em razão da influência judaico-cristã. Para o deontologista, a fonte do bem está nas ações corretas, que seguem regras ou normas de ação moral. Kant foi um filósofo que usou uma ética deontológica mais racional, não constituída por uma simples lista de regras, mas por um princípio que permite inferir se uma dada ação é moralmente correta e se a regra nela envolvida é moral. Trata-se do imperativo categórico.

O princípio do imperativo categórico pode ser dividido em dois: a) o princípio da universalização, no qual uma ação é moralmente correta quando podemos querer que a máxima que ela envolve se torne uma lei universal válida para todos os agentes; b) o princípio dos fins, no qual uma ação é moralmente correta quando, com ela, tratam as outras pessoas também como fins em si mesmo. Este princípio previne a manipulação e a exploração de outras pessoas. Em resumo, para a filosofia kantiana "o ser humano é um fim em sim mesmo e jamais, deve constituir um meio para atingir determinado fim". 4

$\mathrm{Na}$ Inglaterra, David Ross formulou o princípio de que há certos deveres que são partes da natureza fundamental do universo, adicionando uma estratégia para resolver os casos onde as normas que os prescrevem parecem exigir violação (deveres aparentes ou prima facie e o outro real). ${ }^{2}$

Nas últimas décadas do século XX popularizouse o pensamento de Rawls, ${ }^{5}$ da justiça enquanto equidade. Este defendeu ser justa a ação que tenha consequências desiguais para os diversos envolvidos, apenas quando resultam em benefícios compensatórios para cada um, e particularmente para os membros "menos favorecidos", "menos afortunados" da sociedade. Esta teoria contrapõe-se ao utilitarismo anglo-saxônico. A equidade seria uma desigualdade aplicada a uma "boa causa", tendo como função minimizar os efeitos da loteria social, priorizando as necessidades dos "mais desfavorecidos". Os pensadores da teoria da justiça se opõem ao utilitarismo, pois vêem diversos problemas no cálculo do utilitarismo, já que este mede a moralidade por suas consequências. Entre estes problemas apontam especialmente a incerteza e a infinitude. No primeiro, as consequências exatas de um ato não são determináveis até que ele aconteça de fato. Um ato aparentemente inocente pode se mostrar imoral à vista de suas consequências reais, assim como um ato supostamente malvado poderá se revelar moral, por exemplo: matar um terrorista. No segundo, as consequências podem formar uma cadeia, com efeito, dominó. Desta forma, avaliar as consequências de um ato gera o problema da identificação de suas consequências: quando podemos dizer que um ato não é mais causa? Onde terminará a cadeia de consequências?

\section{Ética consequencialista: utilitarismo}

\section{Utilitarismo clássico: utilitarismo de ato}

Bentham6 (1748 - 1832), na Inglaterra foi o criador do utilitarismo com a filosofia moral. Para ele, a felicidade é o bem último (e a infelicidade o mal último) da ação humana e esta é alcançada quando maximizamos o prazer sobre a dor (perspectiva hedonista de felicidade). Define o princípio de utilidade como "aquele que aprova ou desaprova qualquer ação, de um indivíduo particular ou medida de governo, segundo a tendência que tem a aumentar ou a diminuir a felicidade da pessoa cujo interesse está em jogo" (p. 10). ${ }^{6}$

Para mensurar a diferença entre o prazer e a dor, Bentham ${ }^{6}$ sugeriu um cálculo utilitário, que consiste em fazer um balanço do prazer e da dor (intimidade, devoção, certeza, proximidade, fecundidade e pureza) para cada pessoa envolvida, fazendo um balanço final. Nesse balanço se privilegia o prazer sobre a dor para a ação ser moralmente correta; caso contrário será uma má ação. 7

A moralidade de um ato é calculada, não determinada a partir do princípio de um valor utilitarista, levando-se em conta as consequências do ato sobre o bem estar do maior número de pessoas. Para Singer, 8 o cálculo utilitarista do prazer e dor deve incluir todos os seres dotados de sensibilidade. Singer afirma que ética e moral são expressões sinônimas, 
sustentando que não pode haver nenhum tipo de discriminação fundamentada na cor da pele, sexo, inteligência ou espécie, haja vista, que o princípio da igualdade impõe a equivalência dos interesses dos sujeitos, sendo que nenhum interesse deve preponderar sobre o outro. Ele defende que "o princípio da igualdade entre os seres humanos não é uma descrição de fato atual entre os homens; é uma prescrição de como nós deveríamos tratar os seres humanos". 9

O utilitarismo hedonista de Bentham sofreu muitas críticas ao longo do tempo, e por isso, John Stuart Mill reformou a doutrina do seu mestre. Para Mill, 10 na doutrina utilitarista "a felicidade é desejável, e a única coisa desejável, enquanto finalidade; todas as outras coisas são desejáveis como meios para esse fim. A felicidade que forma o padrão utilitarista daquilo que é correto na conduta não é a felicidade do próprio agente, mas a de todos os implicados".

As ações corretas são as que produzem o maior equilíbrio possível entre felicidade e infelicidade. Ele separa a felicidade em dois grupos. As ligadas aos prazeres inferiores, às necessidades físicas de ordem sensorial, possivelmente mais intensas e episódicas, como beber, comer e sexo. Destes devese evitar o excesso. E as ligadas aos prazeres superiores, que, sendo estes de ordem intelectual, estética e social, são mais duradouros e seguros, como apreciar a beleza, a verdade, o amor e a liberdade, o conhecimento e a criação artística.

O hedonismo de Mill10 é sofisticado e leva em conta a qualidade do prazer na promoção da felicidade para o maior número. A conseqüência disso é deixar em segundo plano a idéia de que o prazer é algo que tem uma quantidade que se pode medir em termos de duração e intensidade. É a qualidade do prazer que é relevante e decisiva para Mill. Por isso, sua afirmação de que "É preferível ser um Sócrates insatisfeito a um tolo satisfeito".

Mill10 diz que para que um ato de renúncia ou sacrifício seja nobre, ele deve ter alguma finalidade; ele não é nobre por si mesmo. Um herói que se sacrifica, ao fazê-lo tem um fim em mente, seja o de proteger outros ou de mudar uma situação desaprovada como injusta. E sua ação é boa na medida em que é um meio adequado para este fim. "O herói ou o mártir teriam feito esse sacrifício se não acreditassem que, desta forma, estariam isentando os outros de sacrifícios similares?".11 Não teríamos, portanto, como calcular o saldo de felicidade geral se foi positivo ou não antes da ação ser realizada. Neste caso, poderíamos levar em conta uma distinção feita por Pettit12 entre uma opção e o prognóstico de uma opção. Uma opção é uma possibilidade que o agente está em posição de realizar, uma possibilidade que pode ser realizada. Seu prognóstico são as diferentes maneiras possíveis como a possibilidade poderia vir a ser realizada. Uma opção teria vários prognósticos. Essas posições são reformuladas pela concepção do utilitarismo de regras. ${ }^{12}$

\section{Utilitarismo de regras}

$\mathrm{Na}$ forma clássica do utilitarismo, pressupõe-se que cada ação individual deve ser avaliada em relação ao princípio da utilidade. Por exemplo, quando prestamos falso testemunho, para saber se isso será errado, teríamos que avaliar as consequências desse ato particular (falso testemunho). Este pressuposto causa inúmeras complicações, pois conduz a conclusão de que podemos fazer todo o tipo de coisas questionáveis se tiverem as melhores consequências, quer quantitativa ou qualitativamente. No utilitarismo de regras, uma ação meramente correta é a que segue uma regra cuja adoção produz um bem maior para a sociedade que a adota e a qual ele pertence. O utilitarismo de regras faz justiça ao fato de que, geralmente agimos segundo estas regras, normas ou princípios culturalmente ou socialmente estabelecidos. Sendo assim, o cálculo utilitário é aplicado não às ações, mas às regras nelas envolvidas. Assim, o utilitarismo de regra seleciona um sistema que deve ser seguido, pois, maximiza o bem para o maior número de pessoas.

De acordo com Leite, ${ }^{7}$ Richard Brandt sugeriu que "moralmente errado" significa que uma ação seria proibida por qualquer código moral que todas as pessoas racionais tenderiam a apoiar.

Por exemplo, se uma pessoa presta um falso testemunho contra um inocente, o utilitarismo de regra raciocinaria: "que regras gerais de conduta tendem a promover a maior felicidade?" e não se as consequências deste ato particular seriam boas.

É possível estabelecer regras que vão reger as relações pessoais, e devemos aceitá-las por nos trazer em um bem estar geral. O conjunto de regras é estabelecido a partir do princípio de utilidade (maior bem para o maior número) e assim, proporciona as melhores consequências. Determinado qual sistema de regras devemos seguir, poderemos ter critério para determinar se uma ação particular é correta ou não. As ações individuais justificam-se pelo simples fato de seguir normas já estabelecidas. Essas, tendo sido estabelecidas, devem trazer as melhores consequências para o maior número de pessoas e devem ser seguidas como dever moral. Porém, podemos em algumas circunstâncias violá-las? Neste caso, duas 
correntes apresentam-se: o utilitarismo de regras sem exceção e o utilitarismo de regras com exceção. A primeira corrente é sustentada por um conjunto de regras, na medida em que traz melhores consequências para o maior número. Elas devem ser seguidas como dever moral sem exceção. Inevitavelmente há situações em que um ato proibido pelo "conjunto de regras" maximizaria a utilidade, talvez mesmo de forma substancial. O que se deve fazer então? Neste caso, a dificuldade seria que o utilitarismo de regra sem exceção, não leva em conta os conflitos entre as regras. É o que ocorre no caso de pessoas perdidas em uma caverna subterrânea. Teríamos uma situação com duas regras: para salvar a maioria das pessoas (regra 1) é preciso matar uma delas (regra 2). Para cumprir a primeira regra violaríamos a regra seguinte. O que fazer? Qual delas terá precedência? Talvez uma saída fosse estabelecer um conjunto de regras a seguir, definindo previamente qual regra tem precedência em caso de conflito, estabelecendo uma hierarquia entre elas.

O utilitarismo de regras com exceção adota uma estrutura em estabelecer um conjunto de regras que proporcione as melhores consequências. Mas, autoriza a violação de uma regra em uma situação particular, quando essa violação maximiza o bem para o maior número. Assim, o utilitarismo de regra com exceção admite o estabelecimento de um sistema de regras, obtidas a partir do princípio de utilidade. E essas regras indicam como devemos agir ordinariamente. Porém, em circunstância extraordinária (matar um terrorista que está colocando inocentes sobre o risco de vida) podemos violar alguma regra, visto que isso maximizaria o bem geral.

Segundo Costa, ${ }^{2}$ embora o utilitarismo de regras seja problemático, ele continua sendo um princípio de segundo nível extremamente importante, que é subordinado ao utilitarismo de ato. De fato, o utilitarismo de regra é imprescindível, pois é em função dele que geralmente agimos. O cálculo utilitário só costuma ser aplicado em circunstâncias que envolvem alternativas semelhantes razoáveis, sem normas definidas. Assim, normalmente agimos segundo regras que universalizam tipos de ações que a experiência coletiva mostrou que produzem um bem maior para a sociedade. Violar uma dessas regras pode pôr em risco a confiança nesse sistema e na sociedade que o instituiu, o que não se justifica, mesmo que ele produza um bem maior em termos específicos. Pois, esse risco implica um mau potencial ainda maior que o bem maior que poderia ser produzido. Assim, considerando o bem como resultado positivo no balanço entre prazer e dor, uma ação moralmente correta é aquela que segue uma regra para produzir maior bem para a maioria. Mas, sempre que a violação de uma regra produzir um bem maior como o resultado de uma ação, essa regra deve ser violada.

Como vemos, qualquer uma das versões utilitaristas apresentam dificuldades, e por isso, têm sido freqüentemente reformuladas.

\section{Críticas ao utilitarismo}

O princípio utilitarista pode-se resumir na afirmação: a ação correta é aquela que promove o maior grau de felicidade para o maior número de pessoas. A primeira crítica é conhecida como "argumento da impessoalidade" e a segunda "utilitarismo é uma máquina de calcular?".13

Para os defensores do argumento da impessoalidade, o utilitarismo torna o homem a tal ponto impessoal que não seria mais capaz de levar em conta os valores individuais de cada pessoa. Neste caso tudo seria permitido, desde que promovesse a maior felicidade geral e assim, acabaríamos numa ditadura da maioria. Por exemplo, o utilitarista aceitaria como boa a tortura de um prisioneiro se fosse para evitar um atentado de maiores dimensões. $\mathrm{Ou}$ se tivesse que escolher entre duas opções de salvar a vida de cinco pessoas ou a de cem pessoas, o utilitarista escolheria a segunda opção como correta. E se entre essas cinco pessoas estivessem seus filhos, o que fazer? A quem salvar? Situações como essas são problemáticas, não apenas para o utilitarismo, mas para qualquer teoria ética. Pettit12 observa que este é um ataque que se torna relevante apenas em circunstâncias horrendas, pois os críticos do não consequencialismo teriam que defender uma opção tão pouco atrativa quanto à do utilitarista. Em caso de tortura, para salvar vidas inocentes, esta tortura é tão incorreto quanto se opor a ela e deixar que inocentes morram. Neste caso, a ação defendida pelo utilitarista (praticar a tortura para salvar inocentes) qualquer outra teoria ética teria dificuldade em se opor.

$\mathrm{Na}$ segunda crítica, questiona-se o utilitarismo como uma máquina de calcular. Ninguém recusaria que há situações em que não temos tempo para calcular a maior felicidade geral antes de agir. Nas situações em que governantes são pressionados a tomar decisões em um curto espaço de tempo, que atinja um grande número de pessoas, o utilitarismo poderia ser impraticável. Outro problema seria o fato de haver ações cujo valor em grande parte é a espontaneidade. Como calcular o valor de um abraço espontâneo. Mill,11 como Pettit,12 responderam a esta acusação. Mill diz que "os defensores da utili- 
dade sentem-se muitas vezes obrigados a responder objeções como a de que não há tempo, antes da ação, para calcular e ponderar os efeitos de uma linha de conduta sobre a felicidade geral. É exatamente como se alguém dissesse que é impossível orientar nossa conduta pelo cristianismo porque não há tempo para ler todo o velho e o novo testamento nas ocasiões em que devemos fazer alguma coisa".

Mill11 argumenta: dizer que o critério da moralidade não é o princípio da maior felicidade geral, pois em alguns casos não teríamos tempo para calculá-la, é o mesmo absurdo que dizer que "a arte da navegação não está fundada na astronomia, porque os marinheiros não podem calcular carta náutica".

Aprendemos muito, no que diz respeito à moralidade, com o passado da espécie humana. Pettit12 oferece uma objeção, perfeitamente compatível com a afirmação, que é bastante intuitiva, de que não se começa do zero, como completos ignorantes, a cada momento em que se tem que optar por uma ação. A resposta de Pettit12 à questão é que, em uma teoria consequencialista como o utilitarismo, o que justifica uma escolha de uma opção é o fato de ela promover o valor relevante. O utilitarismo não nos diz como deliberar, mas apenas como justificar essa deliberação. Seria, portanto, uma teoria da justificação e não da liberação. O autor afirma então dois tipos de opções: as diretamente comportamentais em que o agente se dispõe a envolver cursos de ação bem determinados, outra podendo envolver, de maneira indireta, um conjunto de outros cursos de ações. O importante é que em cada uma das maneiras que eu posso realizar opção, cada um dos prognósticos representa um diferente estado de coisas. Pettit10 sustenta que todo prognóstico de opção tem um valor determinado, o valor de qualquer opção é uma função dos valores de seus prognósticos.

O utilitarismo, diz Pettit, 12 teria relevância prática na medida em que serve como uma política deliberativa em casos onde o comportamento está indiretamente envolvido.

O critério utilitarista nos ajudaria a deliberar sobre se devemos ou não adotar certo traço de caráter, se devemos ou não adotar certo princípio. O utilitarista não seria obrigado a calcular a maior felicidade geral para dar ou não um abraço, para amar ou não sua esposa. Além disso, ele não deveria ser uma máquina de calcular, não teria que ser capaz de fazer cálculos mesmo quando tivesse um curto espaço de tempo para agir.

\section{Considerações finais}

As teorias utilitaristas defendem que para a avaliação da moralidade dos atos humanos se deva sempre levar em conta as conseqüências, os resultados das ações, se esses propiciarem o "maior bemestar para o maior número possível de pessoas”, ou seja, a maximização do bem-estar. Apesar das dificuldades de se conceituar o que é bem-estar, isto pode significar que, quando são defrontadas duas ou mais opções, dever-se-ia pesar cada uma delas e escolher aquela que trouxesse mais benefícios e na qual fosse eliminado, evitado ou minimizado o dano, o sofrimento, a dor, ou seja, tudo o que for considerado em oposição ao bem, à felicidade do maior número de pessoas envolvidas.

No mundo atual, as ameaças de terrorismo são uma constante. E o princípio da utilidade (nas suas variações) pode ser usado com relativa segurança, sempre tentando promover a felicidade e minimizando o sofrimento das pessoas. Qualquer teoria ética teria dificuldade de se opor a este princípio, como por exemplo em um caso de ameaça terrorista. É importante lembrar que nenhuma acusação feita ao utilitarismo é de fato conclusiva contra ele.

Galvão14 diz "que o utilitarismo de ato estaria disposto a faltar com a palavra sempre que um ato de quebrar promessa maximizasse o bem. O utilitarismo de regras pelo contrário, teria de perguntar pelas conseqüências sociais da ação de uma regra que permitisse quebrar as promessas sobre condições especiais, presumindo que os membros da sociedade saberiam quais seriam essas condições especiais que poderiam ser quebradas".

Marcondes 15 aponta que a perfeição ideal da moral utilitarista encontrar-se na regra de ouro de Jesus de Nazaré. Fazer aos outros, o que gostaríamos que nos fosse feito e amar o próximo como a nós próprios constitui o espírito da ética utilitarista em sua plenitude. Para melhor aproximar-se do ideal utilitarista, estabelece-se que as leis e acordos sociais devam colocar em primeiro lugar a felicidade e, em segundo, a educação e a opinião, que tem tão grande poder sobre o caráter humano. Este poder deve ser usado para estabelecer na mente de cada indivíduo uma associação indissolúvel entre a sua felicidade e o bem de todos; especialmente entre a sua felicidade e os modos de conduta, negativos e positivos, que a preocupação com a felicidade universal prescreve, de tal modo que seria para ele 
inconcebível a possibilidade de obter felicidade para si própria com uma conduta oposta ao bem comum. Mas também de forma que o impulso direto de promover o bem de todos seja em cada indivíduo um dos motivos habituais da ação, e os sentimentos ligados a isso possam ter um papel amplo e proeminente na existência sensível de cada ser humano.

Por tudo isso, acredita-se que o critério utilitarista é adequado a uma situação de risco, e que se pode usar esta teoria ética em situações deste tipo, usando o utilitarismo de regras com exceção para avaliar a ação e suas consequências. As reflexões da bioética podem auxiliar na maximização do consenso sobre as normas práticas que dizem respeito à vida humana e à vida humana em sociedade. 16

A base do comportamento humano é refletir,

\section{Referências}

1. Utilitarismo. [acessado em mar 2009]. Disponível em: http://pt.wikipedia.org/wiki/utilitarismo

2. Costa CF. Razões para o utilitarismo: uma avaliação comparativa de pontos de vista éticos. Ethica [on line]. Dez 2002 [acesso em Mar 2009]; 1(2): 20 p. Disponível em: <http: www.cfh.ufsc.br/ethic@/ETICA4.PRN.pdf>.

3. Aristóteles: Ética a Nicômano (São Paulo: Abril Cultural1976).

4. E. Kant: Die Grundlage der Metaphisk der Sitten (Frankfurt: Gesamte Werke, vol.4,1986.

5. Rawls J. Uma teoria da Justiça. São Paulo: Editora Martins Fontes; 1997.

6. Bentham J. Uma Introdução aos Pricípios da Moral e da Legislação. São Paulo: abril; 1979

7. Leite P. Ética Utilitarista. [on line]. Porto Alegre: Pedro Leite. [acesso em Mar 2009] Disponível em: http://www.pedroleite.pro.br/arquivos/downloads/TEXTOS /\%c3\%89tica\%20utilitarista\%20(P\%20leite).doc

8. Singer P. Ética prática. 3 ed. São Paulo: Ed Martins Fontes; 2002.

9. Singer P. Animal liberation. New York: Harper Collins Publications; 2002. argumentar e oferecer justificativas racionais para que se possam tomar decisões. Em situação de risco o critério do princípio utilitarista pode ser aplicado, pois nela necessita-se de uma postura racional marcante que é característica deste princípio. $\mathrm{O}$ dever do ser humano é sempre buscar antes a minimização do sofrimento à maximização do prazer, já que essas não são simétricas.

O utilitarismo, como critério geral de moralidade pode e deve ser aplicado às ações individuais e políticas, tanto no domínio econômico quanto nos domínios sociais e jurídicos.

Nos dias atuais os princípios utilitaristas são mais utilizados que os deontologicos, principalmente no que se refere a saúde onde o coletivo prevalece sobre o individual e as teorias de Kant muitas vezes ficam relegada a um segundo plano.

10. Mill JS. A Liberdade/Utilitarismo. São Paulo: Ed Martins Fontes; 2000 .

11. Mill JS. Autobiografia. São Paulo: Ed Iluminurias; 2007.

12. Pettit P. Consequentialism. In: Pettit P. A companion to ethics. Oxford: Blackwell; 1991: 230-7.

13. Ferreira SS. Utilitarismo: dois problemas. Portal Philosofia. [on line]. Mar 2009 [acesso em Abr 2009]. Disponível em: http://www.portalphilosophia.org/ index.php?option $=$ com_content\&task=view\&id=122\&item $\mathrm{id}=72$.

14. Galvão P. Teoria da decisão, racionalidade e ética: o utilitarismo de Harsanyi. Trólei Revista de Filosofia Moral e Política [on line] 2004 [acesso em 28 abr 2009] (4): 9 p. Disponível em: http://www.spful.pt/ trolei/tr04-galvao.htm.

15. Marcondes D. Stuart Mill: Utilitarismo. In: Marcondes D. Textos básicos de ética. Rio de Janeiro: Zahar; 2007: 12730

16. Boff L. Ethos mundial: Um consenso mínimo entre os humanos. Rio de Janeiro: Sestante; 2003.

Recebido em 2 de junho de 2010

Versão final apresentada em 29 de outubro de 2010

Aprovado em 1 de dezembro de 2010 